\title{
IMPLEMENTASI FIREWALL PADA SMP YADIKA 5 JAKARTA
}

\author{
Ermand Noor $^{1)}$, Joko Christian Chandra ${ }^{2)}$ \\ ${ }^{1}$ Manajemen Informatika, Fakultas Teknologi Informasi, Universitas Budi Luhur \\ ${ }^{1,2} \mathrm{Jl}$. Raya Ciledug, Petukangan Utara, Kebayoran Lama, Jakarta Selatan 12260 \\ E-mail : ermandtuilan@gmail.com ${ }^{1)}$, joko.christian@budiluhur.ac.id ${ }^{2)}$
}

\begin{abstract}
Abstrak
Pada Sekolah Menengah Pertama (SMP) YADIKA 5 Jakarta, jaringan internet mempunyai peranan yang penting dalam kegiatan belajar mengajar. Beberapa hal yang sangat harus di pertimbangkan ialah siswa dan siswi yang mengakses internet, semua siswa dan siswi yang berada di Lab SMP YADIKA 5 Jakarta dapat dengan bebas mengakses situs internet, kebutuhan akan akses internet saat ini sangatlah penting, baik untuk mencari data informasi dan juga mencari referensi terbaru, terkadang jaringan internet suka disalahgunakan dengan kegiatan yang tidak efisien seperti mengakses media sosial dan mengakses situs streaming sehingga memperlambat kinerja kecepatan akses internet yang sedang digunakan oleh guru SMP YADIKA 5 Jakarta. Untuk itu harus ada cara mengatasi permasalahan diatas maka diperlukan mekanisme Firewall agar pengaturan situs di router mikrotik yang terkoneksi pada komputer menjadi aman. Sebagian masalah yang ada saat ini pada SMP YADIKA 5 Jakarta adalah masih mudahnya para siswa dan siswi untuk mengakses media sosial dan mengakses streaming video. Pada kasus ini penulis berhasil mengimplementasikan konfigurasi Firewall yang diterapkan di SMP YADIKA 5 untuk membatasi akses media sosial dan streaming video.
\end{abstract}

Kata kunci: Firewall, Internet, Router Mikrotik, Winbox

\section{PENDAHULUAN}

\subsection{Latar Belakang}

Perkembangan teknologi jaringan komputer pada saat ini menunjukkan bahwa sistem keamanan sangatlah penting diterapkan bagi suatu sistem jaringan komputer yang terhubung dengan jaringan luar atau internet. Oleh karena itu internet merupakan sebuah jaringan komputer yang sangat terbuka di dunia internasional, hal-hal yang harus di tanggung adalah bagaimana jaminan sebuah keamanan bagi jaringan yang terhubung dengan Internet.

Akses jaringan Internet yang tidak di organisasikan dengan baik pada SMP YADIKA 5 Jakarta sehingga siswa dapat dengan bebas mengakses apa saja dalam Internet dan di pakai secara bersamaan di Lab komputer. SMP YADIKA 5 Jakarta sendiri memiliki 3 ruang Lab komputer dan 72 PC yang terhubung langsung ke jaringan internet dan memiliki kouta bandwidth yang terbatas yaitu 12 Mbps, dengan mudah mengakses internet tersebut banyak siswa yang membuka media sosial dan streaming video pada saat pelajaran berlangsung di Lab.

Adanya firewall dalam layanan router mikrotik dapaat mengatasi permasalahan diatas, firewall secara umum merupakan pelindung jaringan dan sisi dalam maupun sisi luar router lewat port-port yang ada. Dengan adanya layanan router board mikrotik layanan firewall juga bisa digunakan untuk mengatur network mana saja yang dapat mengakses dan tidak diperbolehkan mengakses, dan juga dapat membatasi port-port mana yang bisa masuk dan keluar melewati router guna melindungi jaringan Internet.

Penulis menggunakan layanan mikrotik sebagai salah satu media device yang digunakan untuk menjadi akses pendukung sistem kerja dalam Implementasi firewall secara efisien, dimana bertujuan agar memaksimalkan sistem pembelajaran dalam suatu sekolah.

\subsection{Masalah}

Diperlukan pembatasan untuk membatasi akses media sosial dan membatasi akses streaming video pada jaringan Lab komputer.

\subsection{Batasan Masalah}

Riset ini hanya mencakup perancangan pada firewall yang diperlukan oleh SMP YADIKA 5 Jakarta dan tidak membahas sisi jaringan pada cabang lain.

Riset menggunakan perangkat Mikrotik dengan tipe seri RB-750r2-hEX.

\subsection{Tujuan Penelitian}

Adapun tujuan serta manfaat yang diperoleh pada SMP YADIKA 5 Jakarta, sebagai berikut:

1. Menerapkan konfigurasi firewall menggunakan mikrotik pada SMP YADIKA 5 Jakarta.

2. Mengimplementasikan konfigurasi Layer 7 Protocol untuk memblok akses streaming dah juga media sosial.

3. Mendokumentasikan dan melaporkan hasil report analisa lapangan yang dilakukan 
penulis di tempat riset.

\subsection{Metode Pengumpulan Data}

1. Interview

Wawancara dilakukan dengan mengajukan pertanyaan lisan kepada penanggung jawab tempat riset serta meminta penjelasan seperlunya kepada bagian yang berkaitan dengan objek penelitian.

2. Observasi

Mengumpulkan data-data dengan pengamatan langsung dengan aturan yang berkaitan dengan objek penelitian agat mendapatkan informasi yang dibutuhkan.

3. Library Study

Media pendukung untuk mencari berbagai informasi, penulis menggunakan teknik studi pustaka dengan mengambil beberapa materi berupa buku dan referensi yang berkaitan dengan penelitian.

\subsection{Metode Pengembangan}

Dalam pengembangan jaringan internet pada saat ini merujuk ke model Waterfall. Ada empat tahap yang digunakan pada metode pengembangan jaringan yang digunakan dalam penyusunan tugas akhir sebagai berikut. Tahapan yang digunakan pada metode model Waterfall secara singkat, sebagai berikut:

1. Analisa

Tahapan analisa bertujuan untuk mencari data informasi yang dibutuhkan pengguna dan instansi serta menganalisa kondisi yang ada, sehingga penulis mendapatkan gambaran yang jelas mengenai jaringan komputer yang ada pada instansi tersebut.

2. Desain

Tahapan desain bertujuan agar menentukan spesifikasi lengkap dari komponen-komponen jaringan dan informasi yang sesuai dengan hasil tahap analisa.

3. Implementasi

Mengimplementasikan pada router mikrotik dengan menggunakan konsep Firewall dengan maksud agar dapat melakukan filtering pada setiap alamat sumber (source) dan alamat tujuan (destination).

4. Perawatan

Tahapan ini dilakukan ketika jaringan internet yang sudah dioperasikan. Pada tahapan perawatan ini maka dilakukan proses monitoring, evaluasi, dan maintenance.[1].

\section{LANDASAN TEORI}

\subsection{Jaringan Komputer}

Jaringan komputer merupakan sekelompok komputer otonom yang menghubungkan satu dengan lainnya dengan menggunakan protocol komunikasi melalui media transmisi atau media komunikasi sehingga dapat saling berbagi data dan informasi, program-program, penggunaan bersama perangkat keras seperti printer, hardisk, dan sebagainya.[2].

\subsection{LAN (Local Area Network)}

Local Area Network ialah jaringan lokal yang dapat dibuat pada area yang minim, misalkan dalam satu bangunan atau dalam satu ruangan. Terkadang jaringan lokal disebut juga jaringan private. LAN biasa dipakai pada sebuah jaringan kecil yang memakai resource secara bersama, seperti pemakaian printer secara bersama, penggunaan media penyimpanan secara bersama dan sebagainya. [3].

\subsection{Topologi Jaringan}

Topologi dapat juga diartikan sebagai layout jaringan komputer. Topologi merupakan suatu aturan yang bisa menghubungkan komputer (node) secara fisik. Topologi berkaitan dengan cara komponenkomponen jaringan (seperti: server, workstation, router, switch) saling berkomunikasi melalui media transmisi data.[4].

\subsection{Router Mikrotik}

Mikrotik adalah sebuah nama merek dari sebuah perangkat jaringan, pada mulanya mikrotik hanya sebuah perangkat lunak atau software yang diinstall ke dalam komputer yang digunakan untuk meremote jaringan, akan tetapi dalam perkembangannya pada saat ini telah menjadi sebuah media device jaringan yang andal dan harga yang terjangkau, dan juga banyak digunakan pada level perusahaan penyedia jasa internet (ISP).[5].

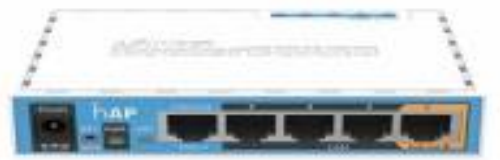

Gambar 1. Router Mikrotik

\subsection{Firewal}

Firewall adalah sebuah peranti keamanan yang berada di ujung koneksi internet anda dan berfungsi sebagai Internet Broder Security Officer (Petugas Keamanan Perbatasan Internet). Secara tetap, peranti ini mengawasi seluruh aliran jaringan internet yang keluar dan masuk ke koneksi, dapat membatasi aliran yang dapat ditolaknya berdasarkan aturan yang sudah ada. Firewall merupakan piranti hukum dan pengamanan di dalam dunia internet yang tanpa hukum. Peranti ini sangat waspada dalam upaya 
mengembangkan misinya untuk melindungi sumber daya jaringan internal yang di hubungkan kepadanya.[6].

\subsection{Layer 7 Protocol}

Aplikasi Layer adalah layanan yang mengimplementasikan komunikasi antar simpul. Aplikasi Layer berfungsi sebagai antamuka antar aplikasi dengan fungsionalitas jaringan yang mengatur bagaimana aplikasi dapat mengakses jaringan dan membuat pesan-pesan kesalahan. Beberapa hal yang dilakukan oleh lapisan aplikasi adalah mengidentifikasi mitra komunikasi, aplikasi transfer data, resource availability, dan lapisan aplikasi terkait dengan aplikasi end-user.[7].

\subsection{Mangle}

Mangle mempunyai fungsi yang dapat menandai sebuah koneksi atau paket data yang melewati route, masuk ke dalam router, ataupun yang keluar dari dalam router. Pada implementasinya Mangle sangat sering digunakan untuk dikombinasikan dengan fitur lain seperti Management Bandwith, Routing policy.[8].

\section{QoS Packet Flow}

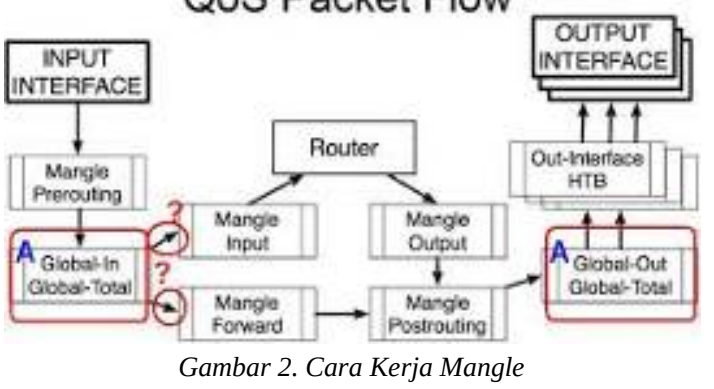

\section{ANALISA JARINGAN}

\subsection{Unit Kerja Lokasi Riset}

Unit kerja yang akan menjadi focus penulisan dalam melaksanakan riset adalah ruangan Lab komputer 1 SMP YADIKA 5 yang berada di lantai 2 tempat lokasi router Mikrotik.

\subsection{Uraian Pemanfaatan}

Pada saat ini pemanfaatan internet di SMP YADIKA 5 antara lain dipakai untuk keperluan:

1) Sebagai penghubung jalur komunikasi antar guru dan murid yang di implementasikan melalui laboratorium komputer untuk keperluan mencari informasi atau mengajar maupun untuk ujian tryout dan UNBK (Ujian Nasional Berbasis Komputer).

2) Sebagai sarana file sharing di tiap lab pada saat ativitas belajar mengajar yang menggunakan laboratorium sebagai media pemebelajaran.

3) Untuk sarana komunikasi denan dunia luar dan juga mengakses komunikasi dengan instansi lain yang bergabung dengan Yayasan YADIKA.

\subsection{Struktur Jaringan Logis Berjalan}

Dari hasil riset yang penulis lakukan pada jaringan SMP YADIKA 5, bentuk topologi logic yang dapat penulis gambarkan sebagai berikut.

Router Mikrotik RB 750 yang berada di lab komputer SMP YADIKA 5:

a) Sumber akses internet berasal dari lab komputer dengan ISP Telkomsel.

b) Router Mikrotik terletak di lab komputer 1, port ethernet 1 tersambung ke internet.

c) Port ethernet 2 terhubung ke switch yang berada di lab komputer 1, lalu switch tersebut terhubung lagi dengan switch DLink 24 port menghubungkan 24 PC yang menerima IP secara DHCP.

d) Port ethernet 3 terhubung ke switch yang berada di lab komputer 2 yang berada di lantai 2, lalu switch tersebut terhubung lagi dengan switch D-Link 24 port menghubungkan 24 PC yang menerima IP secara DHCP.

e) Port ethernet 3 terhubung melalui switch untuk menyambungkan ke lab komputer 3 yang berada di lantai 4, ke ruang TU yang berada di lantai 1 dan ruang guru berada di lantai 2 yang menerima IP secara DHCP.

f) Port ethernet 5 terhubung dengan access point.

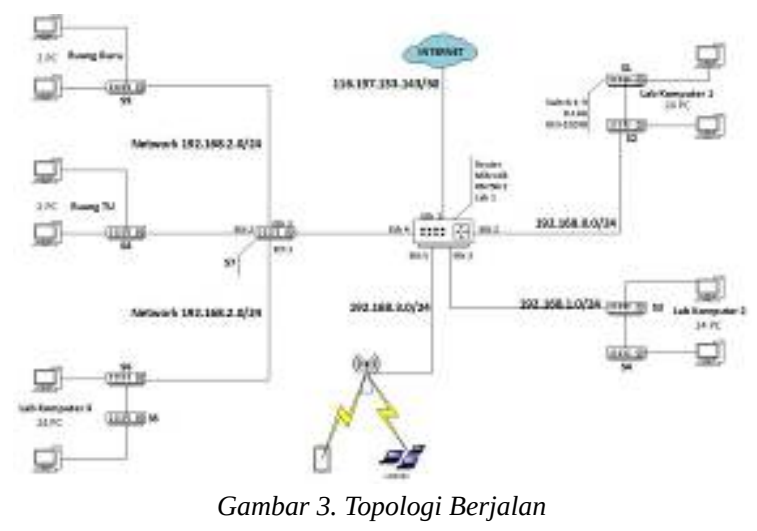

\subsection{Struktur Jaringan Gambar Pemetaan Fisik}

Bentuk topologi fisik berpusat pada router mikrotik yang berada di ruang lab komputer 1 lantai 2 sebagai sumber koneksi internet. Access point berada di lab komputer tersebut berfungsi sebagai Wi-fi untuk ruang lingkup SMP YADIKA 5. Pada 
ruang lab komputer 1 dan lab komputer 2 memiliki 2 switch, switch 1 terhubung ke router mikrotik dan switch 1 terhubung ke pc client. di lab komputer 3 juga memiliki 2 switch, switch 1 terhubung ke router mikrotik melalui switch dan switch 1 terhubung ke pc client. Dan pada ruang TU dan ruang guru juga memiliki 1 switch yang terhubung ke router mikrotik melalui switch.

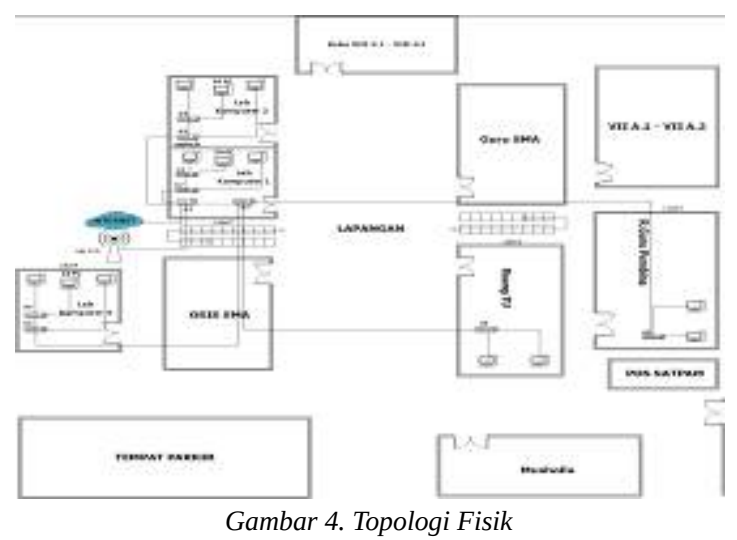

\section{IMPLEMENTASI DAN RANCANGAN JARINGAN}

\subsection{Constraint}

Faktor-faktor yang mempengaruhi penulis untuk membangun sebuah jaringan pada SMP YADIKA 5 Jakarta:

a) Semua user tidak dapat mengakses media sosial pada saat belajar mengajar berlangsung.

b) Meminimalisirkan siswa/i mengakses streaming video pada saat jam pelajaran sedang berlangsung.

c) Memudahkan proses belajar mengajar berlangsung.

\subsection{Infrastruktur Jaringan Usulan}

Jenis Jaringan dan Topologi yang Dipakai

a) Jenis jaringan yang digunakan pada SMP YADIKA 5 Jakarta adalah memakai jenis client-server.

b) Topologi yang dipakai oleh SMP YADIKA 5 adalah jenis topologi star.

\subsection{Rancangan Topologi Logic}

Dari gambaran topologi jaringan di bawah ini layanan internet yang berasal dari ISP, dan juga tersambung langsung pada Router R1, R1 mendapat akses internet dari ISP melalui port ethernet 1 dengan menggunakan IP Address 116.197.133.143/24. pada ethernet 2 terhubung ke ruangan Guru dengan IP Address 192.164.0.1, pada ethernet 3 terhubung ke router R2 yang melalui ethernet 1 dengan IP Address 192.168.1.1/30 sedangkan pada ethernet 1 di router R2 yang terhubung ke router R1 Ethernet 3 dengan IP Address 192.168.1.2/30, pada ethernet 4 terhubung ke ruang TU dengan IP Address 192.168.2.1, dan pada ethernet 5 terhubung dengan access point dengan IP Address 192.168.3.1.

Port-port interface ethernet dari router R2 terhubung dengan 3 buah Lab komputer, masingmasing Lab Komputer 1 dengan IP Address 192.168.10.1/24 terhubung pada ethernet 2, Lab Komputer 2 dengan IP Address 192.168.20.1/24 terhubung pada ethernet 3, Lab Komputer 3 dengan IP Address 192.168.30.1/24 terhubung pada ethernet 4.

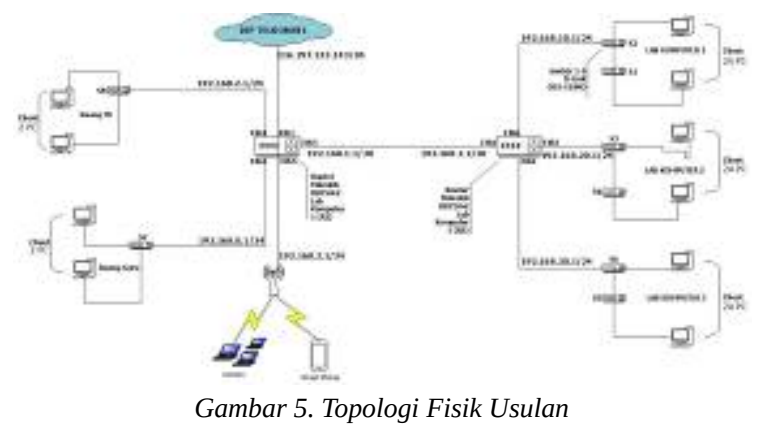

\subsection{Rancangan Jaringan Topologi Fisik Usulan}

Pada rancangan jaringan topologi fisik tidak mengalami perubahan. Penulis hanya saja akan menambahkan router mikrotik seri RB-750r2-hEX untuk mengganti perangkat switch yang sebelumnya digunakan untuk menyambungkan internet ke ruang guru, TU, dan Lab komputer 3 yang berada di ruangan lab komputer 1 yang sama juga dengan penempatan router mikrotik R1.

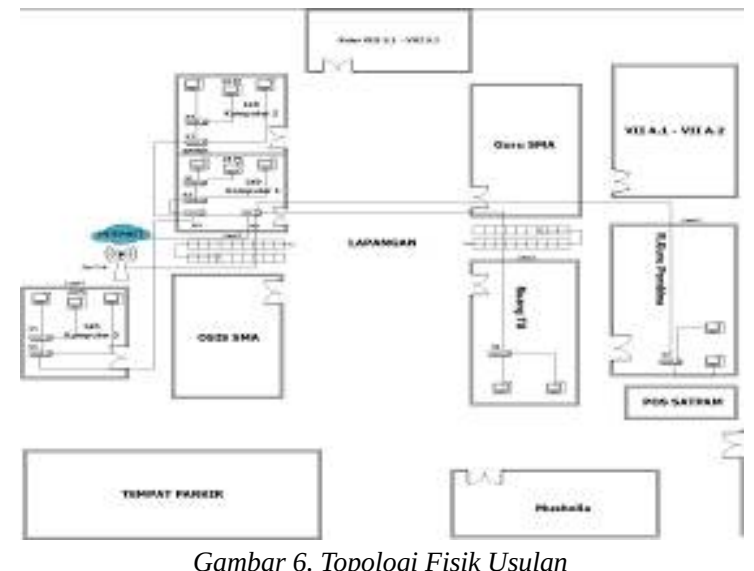

Gambar 6. Topologi Fisik Usulan 


\subsection{Pengalamatan IP Address Usulan}

Pengalamatan IP Address usulan di SMP YADIKA 5 Jakarta Barat, router R1 pada eth1 memiliki IP Address 116.197.133.143/24 untuk terhubung ke ISP, eth2 terhubung ke ruang Guru dengan IP Address 192.168.0.1/24, eth4 terhubung ruang TU dengan IP Address 192.168.2.1/24, eth2 dan eth4 terhubung dengan switch D-Link DES1024D 24 port menerima IP secara dhcp. Sedangkan eth3 terhubung ke router mikrotik R2 dengan IP Address 192.168.1.1/30 untuk router mikrotik R1, dan di router mikrotik R2 terhubung di port eth1 dengan IP Address 192.168.1.2/30.

Pada router mikrotik R2 untuk eth2 terhubung ke lab Komputer 1 yang melewati S1-S2 dengan IP Address 192.168.10.1/24, eth3 terhubung ke lab Komputer 2 yang melalui S3-S4 dengan IP Address 192.168.20.1/24, eth4 terhubung ke lab Komputer 3 yang melalui S5-S6 dengan IP Address 192.168.30.1/24. Untuk switch D-Link yang terhubung router mikrotik R2 semua client mendapat IP Address secara dhcp dan juga menjadi fokus kami dalam melakukan implementasi di router mikrotik R2.

Tabel 1. IP Address Usulan

\begin{tabular}{|c|c|c|c|c|c|}
\hline $\begin{array}{c}\text { Numa } \\
\text { Peranglast }\end{array}$ & Interfioe & IP Addrew & Suteetmak & Netwerk & Keterangan \\
\hline \multirow{3}{*}{$\begin{array}{l}\text { Rouler } \\
\text { Milsotie } \\
\text { RB. } 75002 \text {. } \\
\text { hEX }\end{array}$} & $\begin{array}{c}\text { Eel } \\
\text { (Internet) }\end{array}$ & 116.197 .133 .143 & 255.255 .255 .252 & 116.197 .133 .142 & \multirow{9}{*}{$\begin{array}{c}\text { L.ab } \\
\text { Konupter } \\
1\end{array}$} \\
\hline & Ete2 & 192.168 .0 .1 & 255.255 .255 .0 & 192.168 .0 .0 & \\
\hline & Etas & 192.108.1.1 & 255.255 .255 .252 & 192.168.1.0 & \\
\hline \multirow[t]{2}{*}{ (R1) } & Eet & 192.168 .2 .1 & 255.255 .255 .0 & 192.168 .2 .0 & \\
\hline & Etes & 192.1683 .1 & $255.255 .255 \%$ & 192.1683 .0 & \\
\hline Router & Etet & 192.168 .1 .2 & 255.255 .255 .252 & 192.168 .1 .0 & \\
\hline Milarotik & Ees & 192168.10 .1 & 255.255 .255 .0 & 192168.10 .0 & \\
\hline $\begin{array}{l}\text { RB. } 75002 \text {. } \\
\text { hEX }\end{array}$ & Ets & 192.168 .20 .1 & 255.255 .255 .0 & 192.168 .20 .0 & \\
\hline (R.2) & EteA & 192.168 .30 .1 & 255.255 .255 .0 & 192168.30 .0 & \\
\hline
\end{tabular}

Tabel 2. Pengalamatan IP Address Usulan

\begin{tabular}{|c|c|c|c|c|}
\hline $\begin{array}{c}\text { Nama } \\
\text { Perangkat }\end{array}$ & Ruamgan & $\begin{array}{l}\text { Range IIP } \\
\text { Address }\end{array}$ & Subbetenalk & Gatcway \\
\hline \multirow{5}{*}{$\begin{array}{c}\text { Switch } \\
\text { DES-1024D } \\
\text { (S1-SB) }\end{array}$} & $\begin{array}{c}\text { S1-S2 } \\
\text { Lab Komperter } \\
1 \\
(152.168 .10 .09\end{array}$ & $\begin{array}{c}192.168 .10 .2- \\
192.168 .10 .254 \\
\text { (DHCP) }\end{array}$ & 255.255 .2550 & 192.168 .10 .1 \\
\hline & $\begin{array}{c}\text { S3-S4 } \\
\text { Iab Komperter } \\
\frac{2}{(192.168 .20 .05}\end{array}$ & $\begin{array}{c}102.168 .202- \\
192.168 .20 .254 \\
\text { (DНCP) }\end{array}$ & 255.255 .255 .0 & 192.168 .20 .1 \\
\hline & $\begin{array}{c}55-50 \\
\text { Lab Komperter } \\
3 \\
(192.108 .30 .05\end{array}$ & $\begin{array}{c}192.168 .302- \\
192.168 .30 .254 \\
\text { (DHCI) }\end{array}$ & 255.255 .2550 & 192.168 .30 .1 \\
\hline & $\begin{array}{c}57 \\
\text { Ruang Guau } \\
\text { (192.168.0.09) }\end{array}$ & $\begin{array}{l}192.168 .0 .2- \\
192.168 .0 .254 \\
\text { (DHCP) }\end{array}$ & 255.255 .255 .0 & 192.168 .0 .1 \\
\hline & $\begin{array}{c}\text { S8 } \\
\text { Ruang TU } \\
(192.1682 .0)\end{array}$ & $\begin{array}{l}10216822- \\
192.168 .254 \\
\text { (DHCP) }\end{array}$ & 255.255 .255 .0 & 192.168 .2 .1 \\
\hline
\end{tabular}

\subsection{Konfigurasi}

a. Memberi Nama Interface
Interface -> Pilih Ethernet yang ingin diubah lalu Klik 2x -> Tab General.

Hasil dari interface yang telah diberi nama:

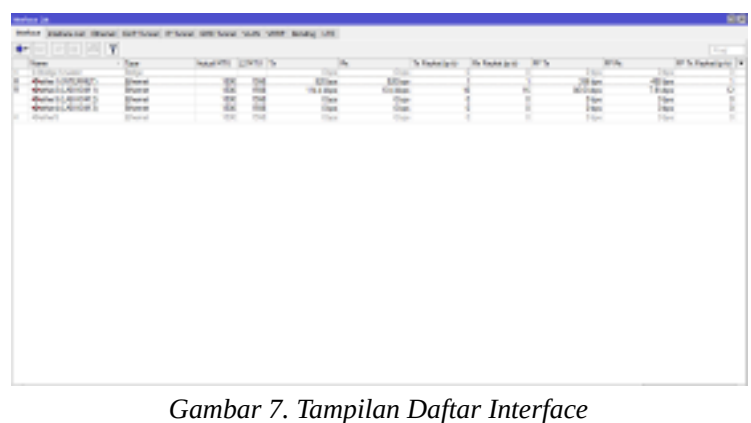

b. Memberikan IP Address pada Interface

Klik IP -> Klik Address -> Kemudian Klik (+)

-> Beri IP address.

Hasil dari interface yang telah diberi ip:

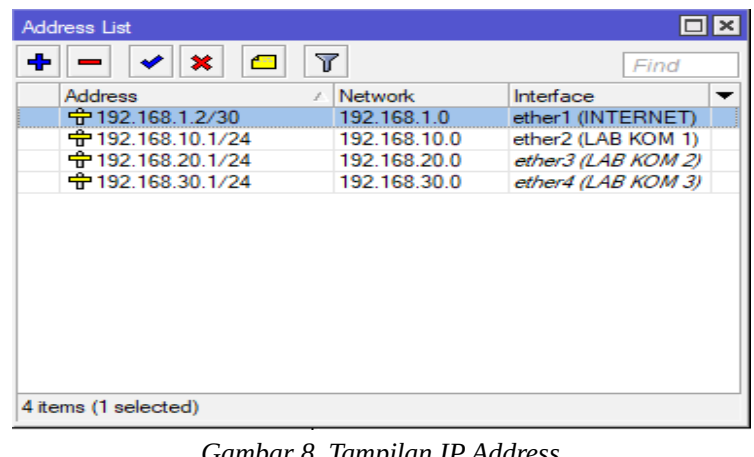

Gambar 8. Tampilan IP Address

c. Setting DHCP Server

DHCP Server untuk memberikan settingan Network, Gateway dan DNS Server untuk Client.

Klik IP-> DHCP Server-> DHCP Setup, pilih Interface yang ingin diberikan IP.

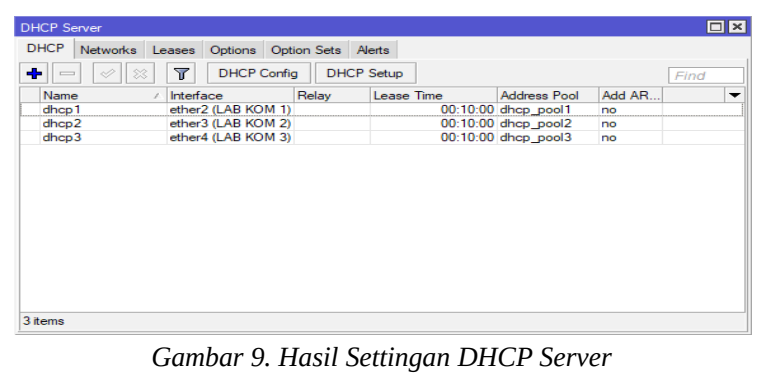

d. NAT Masquerade

NAT Masquerade adalah untuk memberikan keamanan kepada IP Private sehingga ketika IP Private mengakses keluar jaringan maka IP Private itu menjadi IP Public.

Klik IP-> Firewall-> Tab NAT-> Tambah $(+)$ 


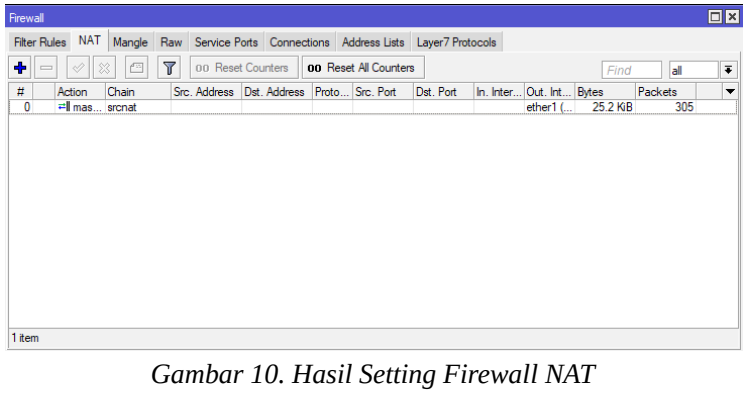

e. IP Pool

IP Pool adalah untuk memberikan Range IP untuk Client.

Klik IP-> Pool-> Tab Pools-> Tambah $(+)$

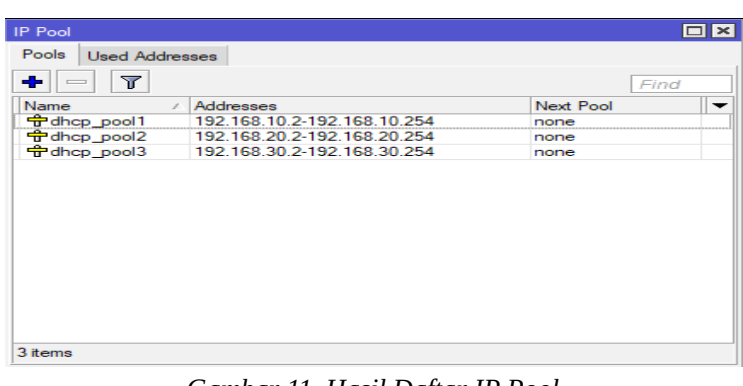

Gambar 11. Hasil Daftar IP Pool

\section{f. Routes}

IP Route untuk menghubungkan mikrotik ke internet dengan menggunakan IP gateway yang terhubung ke Internet.

Klik IP-> Routes-> Tambah (+)-> Pilih Gateway yang terhubung ke Internet.

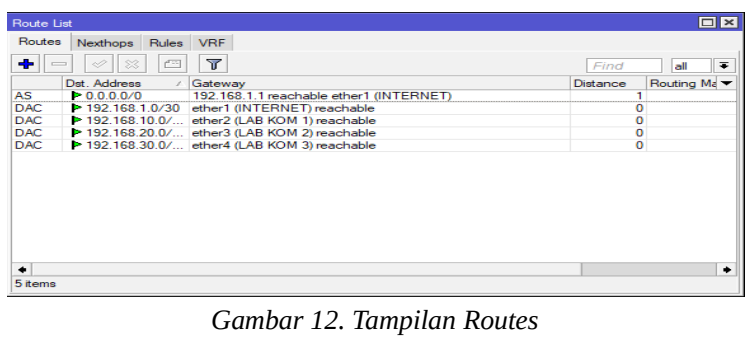

g. Konfigurasi Firewall di Layer 7 Protocol Klik IP-> Firewall-> Layer 7 Protocol-> $\operatorname{Tambah}(+)$

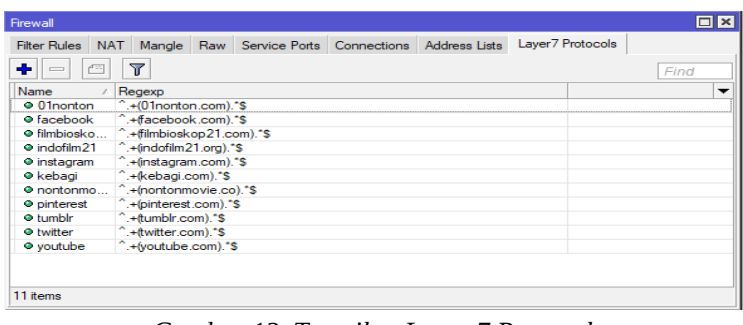

Gambar 13. Tampilan Layer 7 Protocol

h. Konfigurasi Firewall bagian Filter Rules
Klik IP-> Firewall-> Filter Rules-> Tambah $(+)$

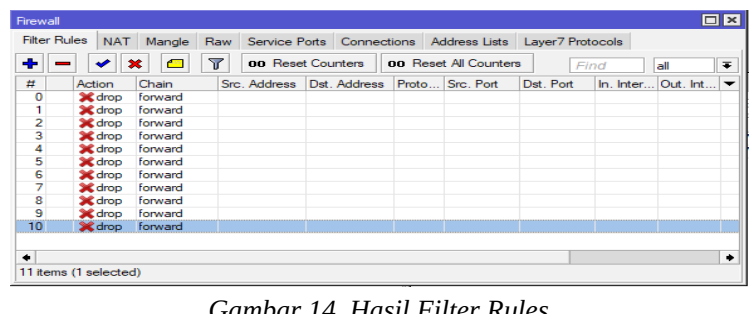

i. Konfigurasi Mangle

Buat Rules Mangle yang akan membuat blacklist IP address yang disebut "fb-block, 01nonton-block, filmbioskop21-block, indofilm21block, instagram-block, kebagi-block, nontonmovieblock, pinterest-block, tumblr-block, twitter-block, youtube-block".

Klik IP-> Firewall-> Mangle-> Tambah $(+)$

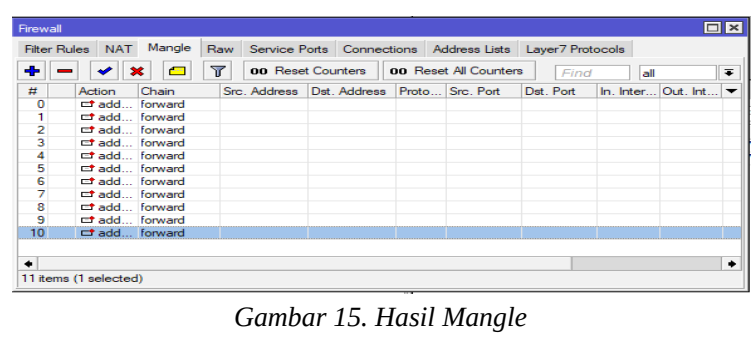

j. Hasil Tampilan Saat Akses Media Sosial dan Streaming Video

1. Tampilan Facebook

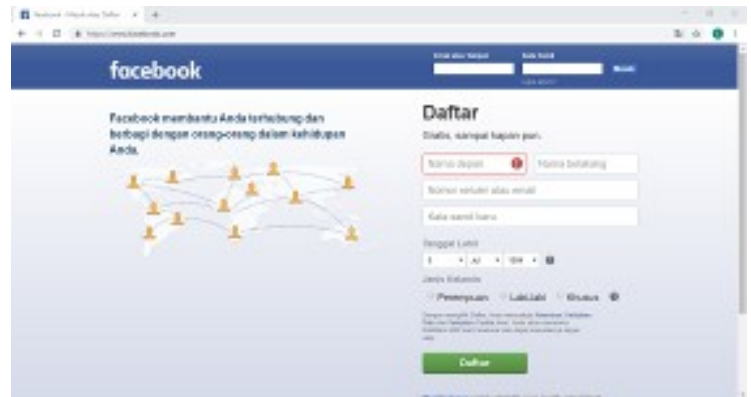

Gambar 16. Tampilan Facebook Sebelum di Block
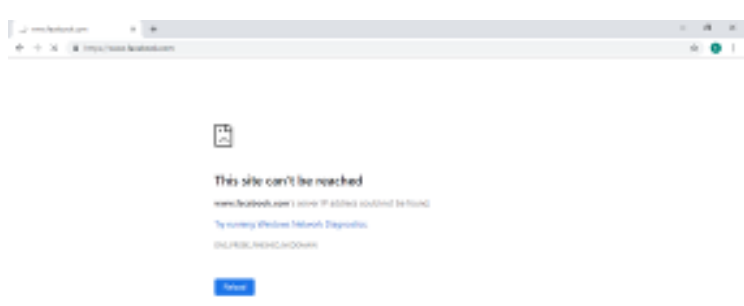

Gambar 17. Tampuilan Facebook Setelah di Block 
2. Tampilan Youtube
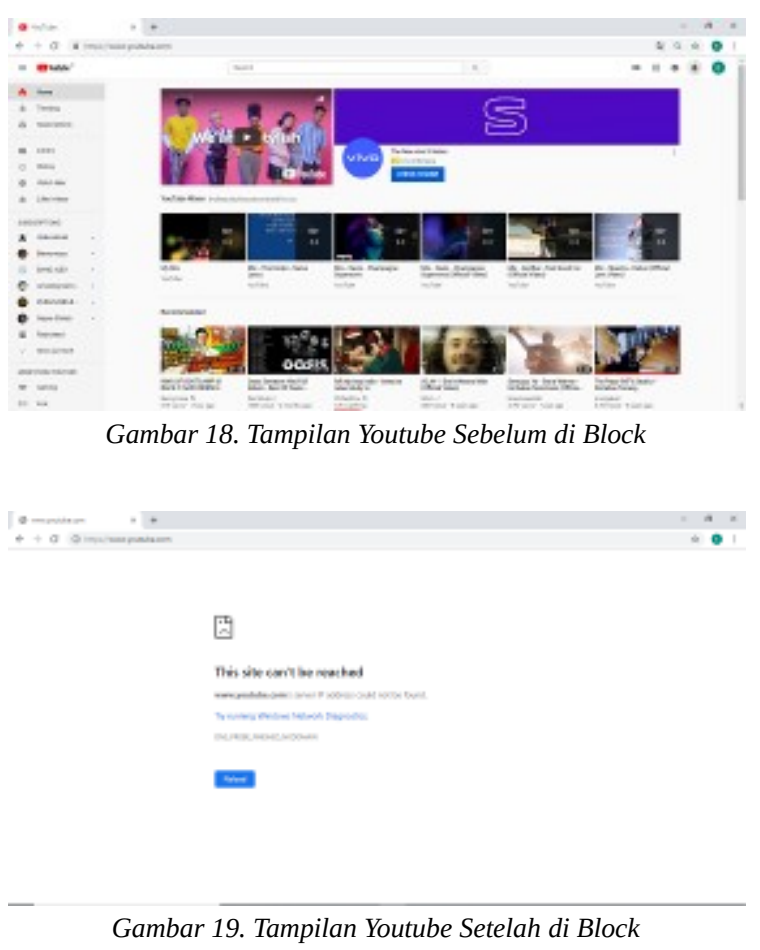

3. Tampilan Instagram

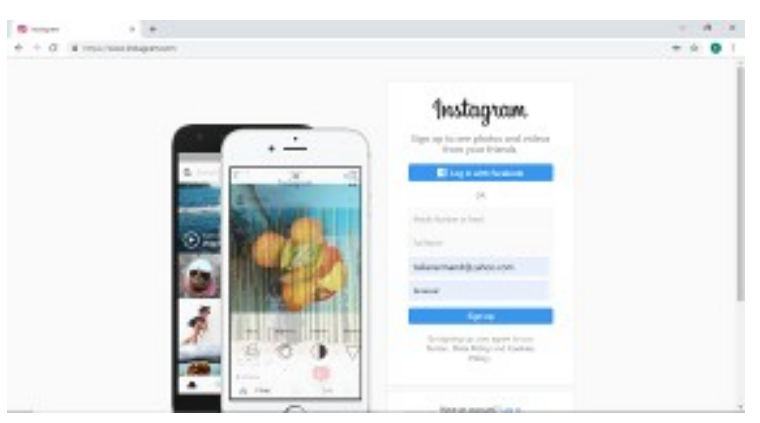

Gambar 20. Tampilan Instagram Sebelum di Block

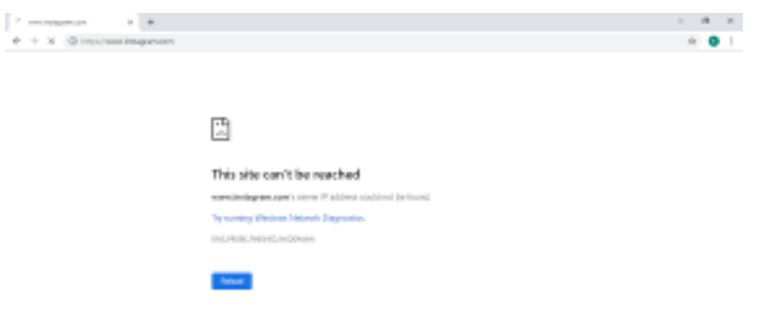

Gambar 21. Tampilan Instagram Setelah di Block

4. Tampilan Nontonmovie

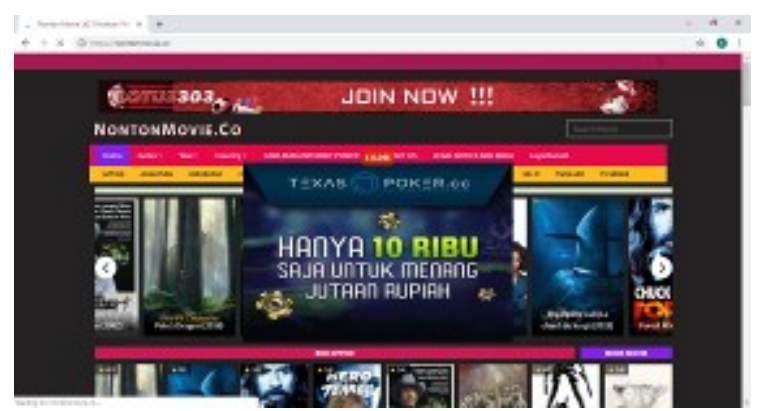

Gambar 22. Tampilan Nontonmovie Sebelum di Block

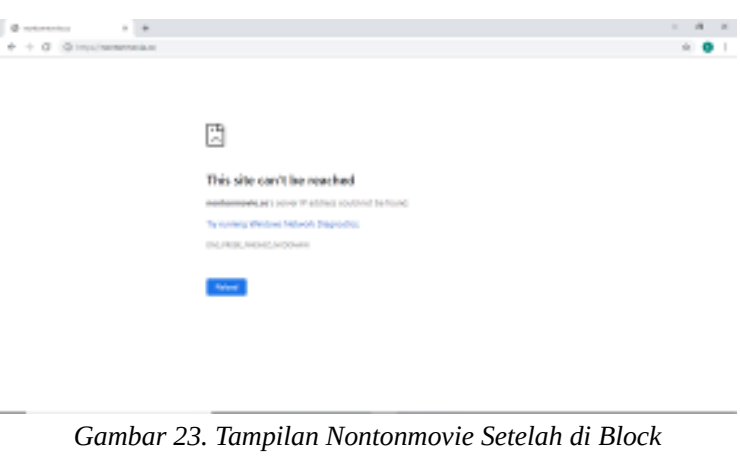

\section{KESIMPULAN}

Setelah melakukan dan juga implementasi yang dibuat pada bab sebelumnya mengenai infrastruktur dan juga studi kasus yang membahas mengenai implementasi Firewall pada SMP YADIKA 5 Jakarta, dapat disimpulkan bahwa:

1. Setelah adanya pembatasan akses media sosial dan pembatasan akses website streaming video di SMP YADIKA 5 Jakarta, bertujuan agar siswa dan siswi dapat lebih fokus pada saat pelajaran berlangsung di Lab.

2. Setelah implementasi, pada saat ini tidak ada lagi siswa dan siswi dapat membuka media sosial dan website streaming video pada saat kegiatan pelajaran berlangsung di Lab.

Berdasarkan kondisi pada kesimpulan diatas, ada beberapa saran dari penulis yang ingin disampaikan yang berguna untuk penulis sendiri maupun SMP YADIKA 5 Jakarta agar apa yang telah dituliskan pada halaman sebelumnya bisa teratasi dan juga bisa menjadi lebih baik lagi. Berikut adalah saran dari penulis:

1. Pemeliharaan perangkat hardware dan aplikasi jaringan yang ada tersedia sangatlah penting agar mencegah dari kerusakan atau hal-hal yang dapat tidak diinginkan sehingga dapat mengakibatkan menurunnya kinerja jaringan internet, sehingga perlu penjadwalan maintenance. 
2. Penambahan media Wireless agar mempermudah akses kebutuhan di SMP YADIKA 5 Jakarta.

\section{DAFTAR PUSTAKA}

[1] Bassil, Y. A Simulation Model for the Waterfall Software Development Life Cycle. International Journal of Engineering \& Technology (IJET), 2(5): 2. 2012

[2] Oetomo, Budi. Konsep dan Perancangan Jaringan Komputer. Yogyakarta: Andi. 2003

[3] Sofana, Iwan. Membangun Jaringan Komputer Mudah Membuat Jaringan (Wire\&Wireless) untuk Pengguna Windows dan Linux. Bandung: Informatika Bandung. 2013

[4] Athailah. Mikrotik Untuk Pemula. Jakarta: Mediakita. 2013

[5] Thomas, Tom. Network Security First-Step. Yogyakarta: Andi OFFSET. 2004

[6] Sukmaji \& Rianto.. Jaringan Komputer Konsep Dasar Pengembangan Jaringan dan Keamanan Jaringan. Yogyakarta OFFSET. 2008

[7] Mikrotik.co.id 2015. Fungsi Mangle (online), di akses pada 19 May 2019 $<$ http://www.mikrotik.co.id/artikel lihat.php? $\underline{\mathrm{id}=146}>$ 